\title{
Natural convection in high temperature flat plate latent heat thermal energy storage systems
}

\author{
J. Vogel *, J. Felbinger, M. Johnson \\ German Aerospace Center (DLR), Pfaffenwaldring 38-40, 70569 Stuttgart, Germany \\ * Corresponding author E-mail adress: julian.vogel@dlr.de
}

\begin{abstract}
The impact of natural convection on melting in high temperature flat plate latent heat thermal energy storage systems is studied with an experimentally validated numerical model in a parameter study with various widths and heights of enclosure dimensions. The storage material is the eutectic mixture of sodium nitrate and potassium nitrate $\left(\mathrm{KNO}_{3}-\mathrm{NaNO}_{3}\right)$. The investigated half widths of the rectangular enclosures between two heated vertical flat plates are 5, 10 and 25 mm; their heights are 25, 50, 100, 200, 500 and $1000 \mathrm{~mm}$. These parameters result in low to very high aspect ratios between 0.5 and 40 and Rayleigh numbers between $1.2 \cdot 10^{4}$ and $1.6 \cdot 10^{6}$. The results are evaluated by dimensional analysis to find general dependencies between enclosure dimensions and natural convection occurrence and strength. To assess the influence of natural convection on the heat transfer enhancement, the convective enhancement factor is introduced. This non-dimensional number is defined as the ratio of actual heat flux by natural convection to a hypothetical heat flux by conduction only. The central findings of the present work are correlations for the mean convective enhancement factor and the critical liquid phase fraction for natural convection onset that are valid for a wide parameter range. The results indicate that heat transfer enhancement due to natural convection increases with greater widths and smaller heights of storage material enclosures. Hence, the vertical segmentation of high enclosures into smaller ones should be considered to enhance heat transfer during charging.
\end{abstract}

\section{Keywords}

High temperature flat plate latent heat storage; Phase change material (PCM); Melting and solidification; Natural convection; Parameter study of rectangular enclosure dimensions; Numerical simulation (CFD).

\section{Nomenclature}

Latin

A aspect ratio

$A$ surface area, $[A]=\mathrm{m}^{2}$

$a$ thermal diffusivity, $[a]=\mathrm{m}^{2} / \mathrm{s}$

$B$ momentum source term coefficient,

$[B]=(\mathrm{Pa} \mathrm{s}) / \mathrm{m}^{2}$

b buoyancy term in the momentum equation,

$[\boldsymbol{b}]=\mathrm{Pa} / \mathrm{m}$

C mushy region or mushy zone constant, $[C]=(\mathrm{Pa} \mathrm{s}) / \mathrm{m}^{2}$

$c_{p} \quad$ isobaric specific heat capacity, $\left[c_{p}\right]=\mathrm{J} /(\mathrm{kg} \mathrm{K})$

$D$ temperature deviation between simulation and experiment, $[D]=\mathrm{K}$

$f_{l} \quad$ liquid phase fraction

Fo Fourier number gravity constant, $[g]=\mathrm{m} / \mathrm{s}^{2}$

height of enclosure, $[H]=\mathrm{m}$

specific enthalpy, $[h]=\mathrm{J} / \mathrm{kg}$

index variable

latent heat of fusion, $[L]=\mathrm{J} / \mathrm{kg}$

number of simulation / measurement values

heat conductivity, $[k]=\mathrm{W} /(\mathrm{m} \mathrm{K})$

pressure, $[p]=\mathrm{Pa}$

heat transfer rate, $[\dot{Q}]=\mathrm{W}$

heat flux, $[q]=\mathrm{W} / \mathrm{m}^{2}$

constant in momentum source term equation

Prandtl number

Rayleigh number
$S_{h} \quad$ source term in the energy conservation equation, $\left[S_{h}\right]=\mathrm{W} / \mathrm{m}^{3}$

$\boldsymbol{S}_{\boldsymbol{u}}$ source term in the momentum conservation equation, $\left[\boldsymbol{S}_{\boldsymbol{u}}\right]=\mathrm{Pa} / \mathrm{m}$

Ste Stefan number

$T$ temperature, $[T]={ }^{\circ} \mathrm{C}$

$t \quad$ time, $[t]=\mathrm{s}$

$\boldsymbol{u} \quad$ velocity vector, $\boldsymbol{u}=(u, v)^{\top}$

$u \quad x$-velocity, $[u]=\mathrm{m} / \mathrm{s}$

$v \quad y$-velocity, $[v]=\mathrm{m} / \mathrm{s}$

$W \quad$ width of enclosure, $[W]=\mathrm{m}$

$x, y, z \quad$ space coordinates, $[x, y, z]=\mathrm{m}$

Greek

$\alpha \quad$ heat transfer coefficient, $[\alpha]=\mathrm{W} /\left(\mathrm{m}^{2} \mathrm{~K}\right)$

$\beta \quad$ thermal expansion coefficient, $[\beta]=1 / \mathrm{K}$

$\epsilon \quad$ convective enhancement factor

$\theta \quad$ error in temperature measurement, $[\theta]=\mathrm{K}$

$\mu \quad$ dynamic viscosity, $[\mu]=\mathrm{Pa} \mathrm{s}$

$v \quad$ kinematic viscosity, $[v]=\mathrm{m}^{2} / \mathrm{s}$

$\xi \quad$ confidence factor in error calculation

$\rho \quad$ density, $[\rho]=\mathrm{kg} / \mathrm{m}^{3}$

\section{Subscripts}

0 initial value

cold cold wall

cond hypothetical case with only conduction

crit critical value for the onset of natural convection 
exp experimental

HTF heat transfer fluid

hot hot wall

$l \quad$ liquid

m melting, fusion

ref reference temperature

s sensible

\section{Introduction}

Thermal energy storage is an important component of the energy storage mix required to increase the usability of temporally fluctuating sustainable energy sources, such as solar and wind energy. With increasing use of these sustainable energy sources, we will be able to answer the growing demand of electricity with reduced carbon dioxide emissions [1].

Latent heat thermal energy storage systems (LHTES) provide a high storage density by utilizing the enthalpy of fusion of a phase change material (PCM) during melting from solid to liquid. They also have the advantage of a constant temperature while changing phase. With a twophase heat transfer fluid (HTF), which also changes its phase during charging or discharging, the temperatures of both the PCM and the HTF remain constant and the required temperature difference becomes minimal. This reduces entropy generation and results in reduced exergy losses [2]. Several storage materials have been used in LHTES systems, which are mostly grouped into organic materials (e.g. paraffin, fatty acids), inorganic materials (e.g. nitrate salts, metals) or eutectic mixtures of two or more components. Applications of LHTES range from low temperature to high temperature and domestic to industrial systems. Common designs of LHTES systems include encapsulated PCM modules, heat exchangers with shell and tube design or heat exchangers with flat plate design. A general overview of storage materials, applications and designs is given by several publications [3-9]. Recent industrial applications with a demand for high temperature LHTES systems include solar thermal power plants with direct steam generation [10] and facilities with process heat or steam [11].

However, the technology of LHTES systems is not yet sufficiently developed and needs further research to enhance efficiency and reduce costs. One of many research questions is how natural convection in the liquid phase of the storage material influences the phase change process. To our knowledge, one of the earliest investigations on phase change with natural convection was done by Szekely and Chhabra [12] in a solidification experiment. Melting was likely first studied by Hale and Viskanta [13]. Since these early works, several proficient analyses have been dedicated to the topic. A review by Dhaidan and Khodadadi [14] gives an overview on melting with natural convection in different geometries. Further research on melting in rectangular geometries was done in the following research works: Bareiss and Beer [15] experimentally studied a rectangular enclosure with different heights heated on one side and cooled on the other side. Nusselt correlations as well as analytic solutions for the melting process were found. Bénard, Gobin and Martinez [16] experimentally and

$\begin{array}{ll}\text { sim } & \text { simulated } \\ \mathrm{w} & \text { wall } \\ \text { Symbols } & \\ \nabla & \text { nabla operator: } \nabla=(\partial / \partial x, \partial / \partial y) \\ \Delta & \text { finite difference, Laplace operator } \Delta=\nabla^{2}\end{array}$

numerically studied the melting process in a rectangular enclosure and also provided an analytic solution of the liquid fraction evolution over time. Jany and Bejan [17] enhanced the scaling theory of natural convection melting in an enclosure and give correlations for the Nusselt number and melting front. Another thorough investigation concerning an electric storage heater with a PCM contained in rectangular enclosures between flat plates was done by Farid and Husian [18]. With an experimental storage unit, they derived a correlation for an effective thermal conductivity to be used in one-dimensional numerical models. Shatikian, Ziskind and Letan $[19,20]$ conducted an investigation of a PCMbased heat sink with internal fins and different enclosure dimensions, in which they scaled the results with the relevant non-dimensional groups.

The mentioned research provides many insights into the melting process with natural convection. However, the results are not directly applicable to flat plate LHTES systems, due to several reasons. The differences between the researched systems and the LHTES system analyzed here are: 1 ) the systems have a heated and a cooled wall instead of two heated walls, 2) a low temperature organic storage material is used as compared with a high temperature inorganic one, 3) the aspect ratio range does not cover typical enclosure dimensions of flat plate LHTES and, 4) the parameter variation is not sufficient to derive general correlations. In summary, to our knowledge, there is no comprehensive data for high temperature flat plate LHTES systems. It is therefore difficult to predict how natural convection will influence the heat transfer rate in a LHTES system. The coupled physical processes of heat transfer, fluid flow and phase change are difficult to model and general empirical correlations are not available.

To contribute to the stated research demand, we analyze a specific LHTES system of the flat plate heat exchanger type, where PCM enclosures are separated by hollow flat plates. These contain the HTF. In the following, we want to briefly introduce the heat transfer mechanisms in such a storage system, which are derived from the afore mentioned research [12-20]. The charging and discharging heat transfer is illustrated in Figure 1, which shows a symmetric sectional cut of the storage system. 


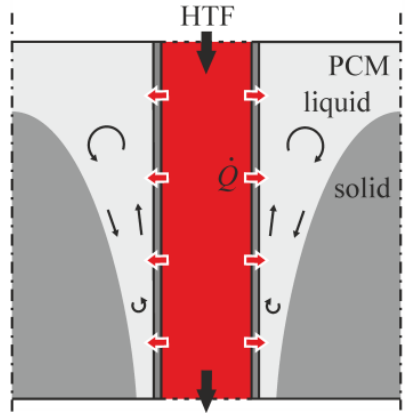

a) Charging (melting)

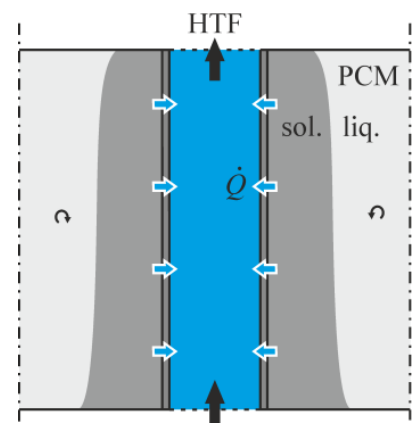

b) Discharging (solidification)
Figure 1: Sectional cut of a flat plate LHTES, in which PCM enclosures are separated by hollow flat plates that contain the HTF.

While charging the storage, heat is transferred from the HTF into the melting PCM. A liquid layer is increasingly formed between the HTF and the phase front. The driving temperature difference in the liquid phase induces a natural convection flow, which enhances the heat transfer rate. While discharging, heat is transferred from the PCM back to the HTF and a solid layer is formed that prevents fluid flow. Only weak natural convection is observed in the liquid layer behind the phase front as long as the liquid is still superheated.

The weak natural convection during discharging can be modeled by heat conduction with an appropriate phase change model. An overview of suitable methods is found, for example, in the review by Dutil [21], in the book chapter by Voller [22] or in the article by Voller and Swaminathan [23]. To account for natural convection, the enhanced conductivity approach [18] may be used. Several heat conduction phase change models with enhanced conductivity were compared to each other and to experimental data while discharging by Pointner et al. [24], where good agreement is found. However, when natural convection is strong, the melting problem becomes highly two-dimensional and the available enhanced conductivity methods achieve insufficient accuracy. For accurate results, the Navier-Stokes system of equations including the energy equation and an appropriate treatment of the phase change has to be solved. In this study, we will use one of many developed models to study the melting process, which is the enthalpy-porosity-method by Voller and Prakash [25].

Our analysis is divided into the following steps: A detailed numerical model of fluid flow and heat transfer by natural convection with melting and solidification based on a commercial software package has been developed. The properties, equations and limitations of the model are presented in section 2. For model validation, we use a lab scale storage unit that has been built, operated and evaluated. We summarize the experimental setup of this storage unit in section 3. Simulating the experimental storage unit with our numerical model and comparing the results to experimental data in section 4 , we find sufficient accuracy. With a parameter study in section 5 , we extend the analysis to a wide range of dimensions with different aspect ratios of height and width. Evaluating the results with dimensional analysis and defining a convective enhancement factor, we can finally derive correlations for the onset and strength of natural convection that are valid for a wide parameter range of flat plate LHTES systems.
The presented research improves the general understanding of natural convection in LHTES systems. The found correlations further enable the estimation of natural convection onset and heat transfer enhancement in flat plate LHTES systems or similar configurations without exhaustive, expensive and time-consuming numerical analyses. Hence, the design process of these systems is facilitated.

\section{Numerical modelling}

A numerical model is used for the calculation of heat transfer in thermal energy storage systems with phase change and natural convection in the liquid phase. It is based on the Navier-Stokes system of equations, which defines the conservation of mass, momentum and energy. The Boussinesq approximation is used to assume constant density but still account for temperature-induced density gradients in the buoyancy term in the momentum equation. The governing equations are transformed with the enthalpyporosity technique by Voller and Prakash [25], which allows the use of a single set of conservation equations for twophase problems by the introduction of an additional variable, the liquid phase fraction.

The numerical model makes use of the following physical simplifications: 1) The depth of the rectangular enclosure in the third dimension $z$ is large enough for wall boundary layer effects to be negligible, 2) the flow in the liquid phase of the PCM is incompressible and Newtonian, 3) density change, and hence volume change, of the PCM during melting or solidification is neglected, 4) the Boussinesq approximation is valid, 5) the PCM is a pure substance or a eutectic mixture of multiple substances, resulting in a planar melting front with no instability effects such as dendrite formation, 6) the sharp interface between the solid and liquid phase of a real pure substance or a real eutectic mixture is represented by a narrow so called mushy region, where the material is neither solid nor liquid but a mixture of both phases, 7) the solid phase does not move no sinking of the solid phase and close contact melting occurs, 8) the thermophysical properties of the PCM and the containment material are constant, 9) natural convection in the PCM is assumed to be laminar 10) radiation and viscous dissipation is neglected and 11) heat losses to the environment are neglected.

In the following, the governing equations as well as the discretization in ANSYS Fluent are described.

\subsection{Governing equations}

The conservation equations of mass, momentum and energy used in the numerical model are given: The continuity equation for an incompressible fluid is

$\nabla \cdot \boldsymbol{u}=0$

where $\boldsymbol{u}=(u, v)^{\top}$ is the vector of $x$-velocity $u$ and $y$ velocity $v$. The momentum equation with buoyancy term $\boldsymbol{b}$ and a momentum source term $\boldsymbol{S}_{\boldsymbol{u}}$ is

$\rho \frac{\partial \boldsymbol{u}}{\partial t}+\rho(\boldsymbol{u} \cdot \nabla) \boldsymbol{u}=\mu \Delta \boldsymbol{u}-\nabla p+\boldsymbol{b}+\boldsymbol{S}_{\boldsymbol{u}}$ 
where $\rho$ is the density, $p$ is the pressure and $\mu$ is the dynamic viscosity. Here, $\Delta$ is the Laplace operator. With the Boussinesq approximation and a reference temperature $T_{\text {ref, }}$, the Buoyancy term is

$\boldsymbol{b}=\rho \beta\left(T-T_{\text {ref }}\right)\left(\begin{array}{l}0 \\ g\end{array}\right)$.

The energy equation for the specific enthalpy $h$ with an enthalpy source term $S_{h}$ is

$\rho \frac{\partial h}{\partial t}+\rho \nabla(\boldsymbol{u} h)=k \Delta T+S_{h}$

The energy equation is transformed with the enthalpyporosity method by Voller and Prakash [25]. The central idea of the method is to write the enthalpy $h$ as the sum of the sensible enthalpy $h_{\mathrm{s}}$ and the latent heat content $f_{l} L$ :

$h=h_{\mathrm{s}}+f_{l} L$.

The sensible enthalpy is

$h_{\mathrm{s}}(T)=\int_{T_{\mathrm{ref}}}^{T} c_{p} d T^{\prime}$

and the latent heat content is the product of the latent heat of fusion $L$ and the liquid fraction

$f_{l}=\left\{\begin{array}{cl}0 & \text { if } T<T_{\mathrm{m}} \\ 0 \ldots 1 & \text { if } T=T_{\mathrm{m}} \\ 1 & \text { if } T>T_{\mathrm{m}}\end{array}\right.$

After introducing equation (5) in (4), dropping the subscript s, and defining the energy equation source term as

$S_{h}=\rho \frac{\partial\left(f_{l} L\right)}{\partial t}+\rho \nabla\left(\boldsymbol{u} f_{l} L\right)$,

the original form of the energy equation (4) is obtained with the latent heat content being expressed only in the source term. This way, a single phase discretization of the energy equation may be used for two-phase problems by introducing the source term (8).

To modify the velocities in the mushy region and in the solid [25], another source term is introduced into the momentum equation (2),

$\boldsymbol{S}_{\boldsymbol{u}}=-B \boldsymbol{u}$,

where a parameter $B$ is multiplied with the velocity vector. This parameter has to be zero in the liquid phase to allow for free motion, but it has to be large in the solid phase to force the velocities to near zero values. While different functions fulfil this requirement, most often the Carman-Kozeny equation, which is derived from the Darcy law for fluid flow in porous media, is used in a modified form:

$B=-C \frac{\left(1-f_{l}\right)^{2}}{f_{l}^{3}+q}$.

The original Carman-Kozeny equation would yield an infinite pressure loss if the liquid fraction approached zero. To reduce the pressure loss to a numerically applicable finite value, a constant value $q$ is additionally added in the denominator. In this study, this value is $10^{-3}$. The parameter $C$ is called the mushy region or mushy zone constant and is a model constant, which replaces the physical properties in the Carman-Kozeny equation. It has to be adjusted to the problem, because it will influence the morphology of the mushy region [26]. Investigations on the influence of the value $C$ are found in an article by Shmueli, Ziskind and Letan [27]. They investigate a material with a melting range and find a great variation of results with different values of $C$. However, for PCMs with a melting point, there is only a small mushy region, which is due to the finite control volume size. With a smaller mushy region, the mushy zone constant becomes less important. In this study, values of $10^{5}$ and $10^{6}$ have been used, which showed similar results and sufficient agreement with experiments.

The presented model equations are solved on two different domains with slightly different boundary conditions for the validation in section 4 and the parameter study in section 5 .

\subsection{Discretization in ANSYS Fluent}

The governing equations are discretized with a pressurebased finite volume method and implicit time integration with ANSYS Fluent 14 [28]. The segregated solver is used with the SIMPLE method by Patankar [29] for pressurevelocity-coupling. The second order derivatives in the diffusive terms are approximated by second order central differences, the first order derivatives in the convective terms with a second order upwind scheme. The interpolation of pressure values at the cell faces is done with the PRESTO! scheme [28]. The resulting linear systems are solved with an iterative method with algebraic multigrid acceleration [28].

The two-dimensional geometries are discretized on a rectangular Cartesian mesh. A study to show the independence of the solution from mesh sizing and time step reveals an optimum with a non-equally spaced mesh with cell sizes $0.1 \ldots 0.5 \mathrm{~mm}$ and refinement at the walls and a time step of $0.0125 \mathrm{~s}$. The residual convergence criterions are set to $10^{-3}$ for continuity and momentum equations and $10^{-9}$ for the energy equation.

\section{Experimental setup}

An experimental LHTES system is used for the numerical model validation, see section 4 . It also provides the basis for the geometry, operating and boundary conditions for the parameter study described in section 5 . In the following subsections, the storage system is presented, material properties are given and an error analysis of the temperature measurements is conducted.

\subsection{Storage system}

The storage system is an adaptation of a flat plate heat exchanger specifically designed for thermal energy storage. A lab-scale prototype feasible for operating temperatures up to $300{ }^{\circ} \mathrm{C}$, as illustrated in Figure 2, has been built and operated by Johnson et al. [30]. 


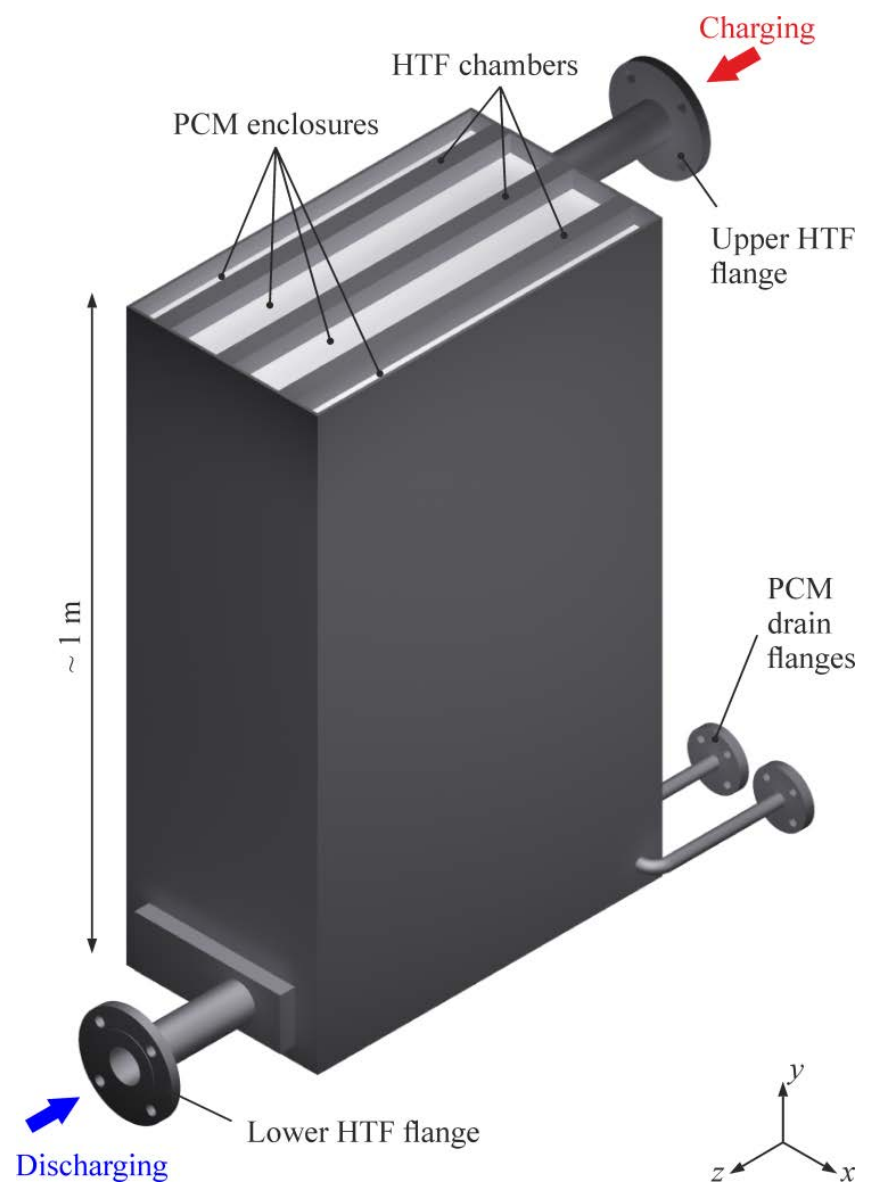

Figure 2: Experimental storage unit in a flat plate heat exchanger design that consists of heat transfer fluid (HTF) chambers and phase change material (PCM) enclosures. The HTF flows downwards while charging and upwards while discharging and is connected to the testing system by two flanges.

The storage system contains rectangular enclosures filled with PCM that are open to the atmosphere. This storage unit for testing and proof-of-concept purposes is comprised of two outer, smaller PCM chambers to reduce the impact of environmental heat losses on the two inner, wider PCM chambers used for analysis. Each PCM chamber has a drain flange for disassembling purposes.

In this setup, the PCM is heated or cooled by thermal oil as the heat transfer fluid (HTF). It flows through HTF chambers in three flat plate enclosures between the PCM chambers and is connected to the HTF sink or source, at two outlet/inlet flanges. The storage unit is integrated in a heating/cooling loop with a maximum flow rate of $3 \mathrm{~m}^{3} / \mathrm{h}$, a heating power of $12 \mathrm{~kW}$ and a cooling power of $30 \mathrm{~kW}$. The photograph in Figure 3 shows the integrated storage system.

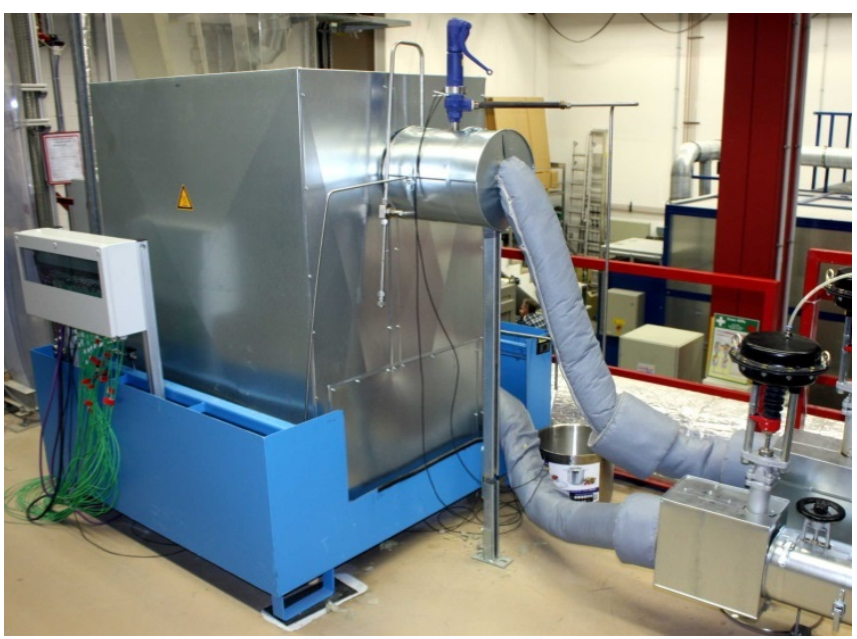

Figure 3: Integration of experimental storage unit in heating and cooling loop.

The open chamber design of the storage allows for an adjustment of the transferred heat rate by the insertion of heat transfer structures. The storage design can thereby be adapted for different application requirements. Various structural geometries have been theoretically and experimentally analyzed by Johnson, Fiß and Klemm [31]. However, for the current validation of the simulation model, only the PCM chambers without heat transfer structures are analyzed.

During experimental testing, temperatures are measured in the HTF at the inlet and outlet flanges and in the PCM at different positions at half of the vertical height in the PCM chambers. The distance of the measurement positions from the bottom is $0.5 \mathrm{~m}$. The distribution of the thermocouple measurement positions in the PCM chambers is depicted in Figure 4. In one of the middle chambers, temperatures are measured at three different positions over the width of the chamber. For comparison, the middle position is also measured in the other wide PCM chamber. At each of these positions, seven thermocouples are fixed in metal plates at the desired measurement position. The distance between measurement points per plate is $10 \mathrm{~mm}$. Two additional measurement points are in the outer PCM chambers.

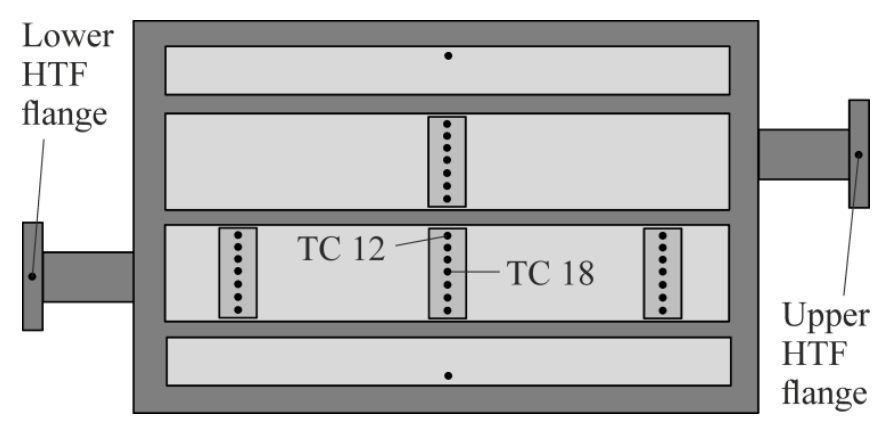

Figure 4: Temperature measurement positions of thermocouples in the storage system from above. The height of measurement positions above the enclosure base is $0.5 \mathrm{~m}$, at the middle of the enclosure.

\subsection{Material properties}

Material properties for the PCM, which is the eutectic mixture of sodium nitrate and potassium nitrate $\left(\mathrm{KNO}_{3}-\right.$ $\mathrm{NaNO}_{3}$ ), have been characterized by Bauer, Laing and Tamme [8]. The eutectic mixture is obtained with 54 wt. \% 
$\mathrm{KNO}_{3}$ and $46 \mathrm{wt} \% \mathrm{NaNO}_{3}$. For the pure substance, the melting temperature is $222^{\circ} \mathrm{C}$ and the latent heat is $108 \mathrm{~kJ} / \mathrm{kg}$. However, technical grade material used for experiments has a differing melting temperature and latent heat. The storage material used here was characterized to have a melting temperature of $219.5^{\circ} \mathrm{C}$ and lower latent heat of $94 \mathrm{~kJ} / \mathrm{kg}$. The containment material is carbon steel 1.0425. The most relevant material properties used in the simulations are given in Table 1 . Constant properties are used at a temperature about the melting point in the liquid state.

Table 1: Thermophysical material properties of the PCM $\left(\mathrm{KNO}_{3}\right.$ $\mathrm{NaNO}_{3}$, ${ }^{*}=$ measured values of technical grade material) and the steel used for the containment.

\begin{tabular}{lccc}
\hline Material property & Unit & $\begin{array}{c}\mathrm{PCM} \\
\left(\mathrm{KNO}_{3}{ }^{-}\right. \\
\left.\mathrm{NaNO}_{3}\right)\end{array}$ & $\begin{array}{c}\text { Steel } \\
1.0425\end{array}$ \\
\hline Density $\rho$ & $\mathrm{kg} / \mathrm{m}^{-3}$ & 1959 & 7800 \\
Heat capacity $c$ & $\mathrm{~J} /(\mathrm{kg} \mathrm{K})$ & 1492 & 540 \\
Therm. conduct. $k$ & $\mathrm{~W}$ & 0.46 & 51 \\
$\begin{array}{l}\text { Melting point } T_{\mathrm{m}} \\
\text { Latent heat } L\end{array}$ & $\left.{ }^{\circ} \mathrm{C} \mathrm{K}\right)$ & $222\left(219.5^{*}\right)$ & - \\
$\begin{array}{l}\text { Therm. exp. coeff. } \\
\beta\end{array}$ & $1 / \mathrm{kg}$ & $108\left(94^{*}\right)$ & - \\
$\begin{array}{l}\text { Dynamic viscosity } \\
\mu\end{array}$ & $\mathrm{Pa} \mathrm{s}$ & $5.5 \cdot 10^{-4}$ & - \\
\hline
\end{tabular}

\subsection{Error analysis of temperature measurements}

Temperatures are measured at various locations in the PCM chambers, as shown in Figure 4, with thermocouples of type $\mathrm{K}$ (Class 1 ). Their measurement tolerance, as given by the supplier, is $\pm 1.5 \mathrm{~K}$. Additional error sources are uncertainties in the positioning of the thermocouples. Even after precisely positioning the thermocouples, the repetitive phase change in the storage material can lead to a deformation of thermocouples and, hence, to a change of the measurement tip position. Additional mounting structures were not used, because they would inhibit the flow in the vicinity of the measurement positions and lead to conduction from the heat transfer surfaces to the thermocouples. The positioning error may be estimated by comparing different symmetric measurement positions in the storage. On average, this leads to an error estimate of $\pm 1 \mathrm{~K}$. However, maximum values of deviations may be much larger during rapid temperature changes at the beginning or end of the phase change. Finally, the statistic error is assessed by comparing different experimental runs. The statistic error of a single measurement run compared to the mean value of four different runs is $\pm 0.4 \mathrm{~K}$ for all measurement positions. Adding up all the errors leads to an estimated error of $\theta= \pm 2.9 \mathrm{~K}$.

\section{Validation}

To assess the accuracy and plausibility of the numerical modelling approach described in section 2, the numerical model is used to perform a simulation of the experimental storage system introduced in section 3. In the following, the numerical model of the storage system is described and then simulation results are compared to experimental data.

\subsection{Numerical model of the storage system}

The numerical model used in this study is an approximate representation of the storage system illustrated in Figure 2. From the 3D physical geometry, only the twodimensional mid-plane is simulated. It is assumed that the boundary effects at the end walls in the third dimension $(z$ direction), have a negligible effect on the simulation domain in the mid-plane. The symmetry of the storage system allows for further simplification, so that only half of one of the inner enclosures containing the PCM is regarded.

The resulting simulation domain shown in Figure 5 consists of a solid zone for the wall and a liquid zone for the PCM of the halved PCM enclosure. Boundary conditions, dimensions and temperature measurement positions are also illustrated in this figure. The top and bottom boundaries are adiabatic, as heat losses are minimized with a sufficient insulation. The right side boundary is a slip wall, because of the symmetry condition. The top side is assumed as a slip wall, because the shear forces of the air layer on top of the PCM are negligible.

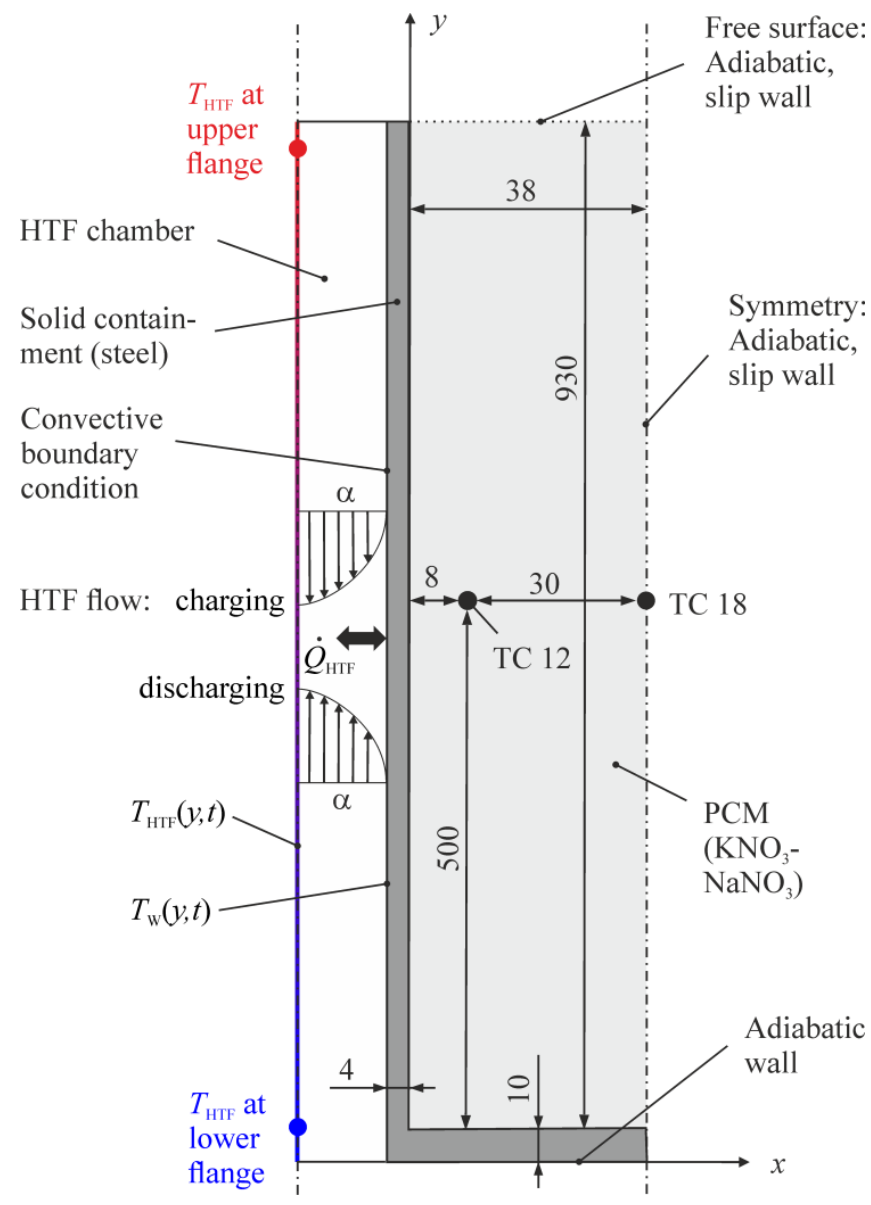

Figure 5: Simulation domain of the storage unit with dimensions given in mm. This 2D-domain is located in the mid-plane of the storage unit, where the thermocouple measurement positions are located. The symmetry of the storage unit allows for the simulation of only half of one inner PCM enclosure; hence, the domain is bounded by symmetry lines at the left and right sides. 
The three-dimensional flow of the HTF in the flat plates is not simulated. In this model, only the simulation of the PCM and not that of the HTF is of interest. Hence, on the left side of the simulation domain, see Figure 5, a convective boundary condition is used to approximately model the heat flow from the HTF into the storage. The heat flow rate $\dot{Q}_{\mathrm{HTF}}$ depends on the heat transfer coefficient $\alpha$, the heated wall area $A_{\mathrm{w}}$ and the temperature difference between the HTF temperature $T_{\mathrm{HTF}}(y, t)$ and the wall temperature $T_{\mathrm{w}}(y, t)$, which both depend on the $y$-position and time $t$. The heat flux $q^{\prime \prime}=\dot{Q}_{\mathrm{HTF}} / A_{w}$ can be expressed locally as:

$q^{\prime \prime}(y, t)=\alpha\left(T_{\mathrm{HTF}}(y, t)-T_{\mathrm{w}}(y, t)\right)$.

The heat transfer coefficient is determined to be approximately constant at a value of $\alpha=200 \mathrm{~W} /\left(\mathrm{m}^{2} \mathrm{~K}\right)$ by Johnson et al. [30]. The temperature $T_{\mathrm{HTF}}(y, t)$, which is obtained from experimental data, is only available at the HTF upper and lower flange positions, see Figure 5. In order to obtain a value of $T_{\mathrm{HTF}}(y, t)$ for the complete height of the simulation domain, the HTF temperature is linearly interpolated. This results in a linear variation of the HTF temperature over the height, which is an approximation of the temperature variation in the HTF flow.

The calculation of this boundary condition is performed in MATLAB and is coupled with ANSYS Fluent CFD simulations with a dynamic simulation control interface: Using ANSYS Fluent as a server, the simulation setup, control and calculation of dynamic boundary conditions are done with MATLAB. The data is transferred between MATLAB and ANSYS Fluent with a dynamic two way interface, which is set up as follows: ANSYS Fluent is started in server mode and MATLAB is connected to the Interface that was generated by Fluent. Then, all of the Fluent text user interface (TUI) commands can be used in a MATLAB application. This way, Fluent may be instructed to set various parameters, perform time step iterations and read and write files. The co-simulation procedure is shown in Figure 6.

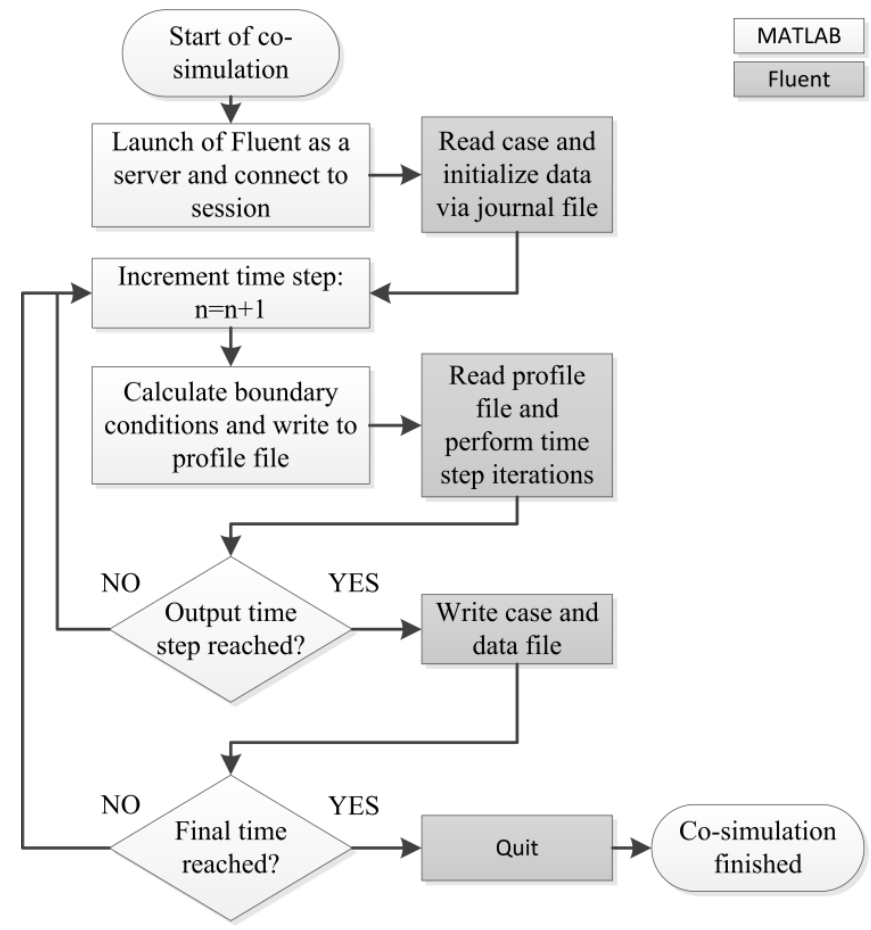

Figure 6: Co-simulation procedure to calculate boundary conditions and control the Fluent model in MATLAB using the Fluent as $a$ server functionality. MATLAB tasks are shown in light grey and Fluent tasks are shown in dark grey. After initialization, there is an inner loop for time step iterations and an outer loop to write case and data files in Fluent. The loops continue until the final time is reached.

\subsection{Comparison of simulation results to experimental data}

The numerical simulations of the charging and discharging processes are compared to experimental data obtained from the storage system. Both the charging and discharging processes are shown in Figure 7. Simulated temperatures (lines) at positions TC12 and TC18, see Figure 5 , are compared to thermocouple measurements (symbols), see Figure 4. For experimental measurements, error bars are shown as calculated in section 3.3. 

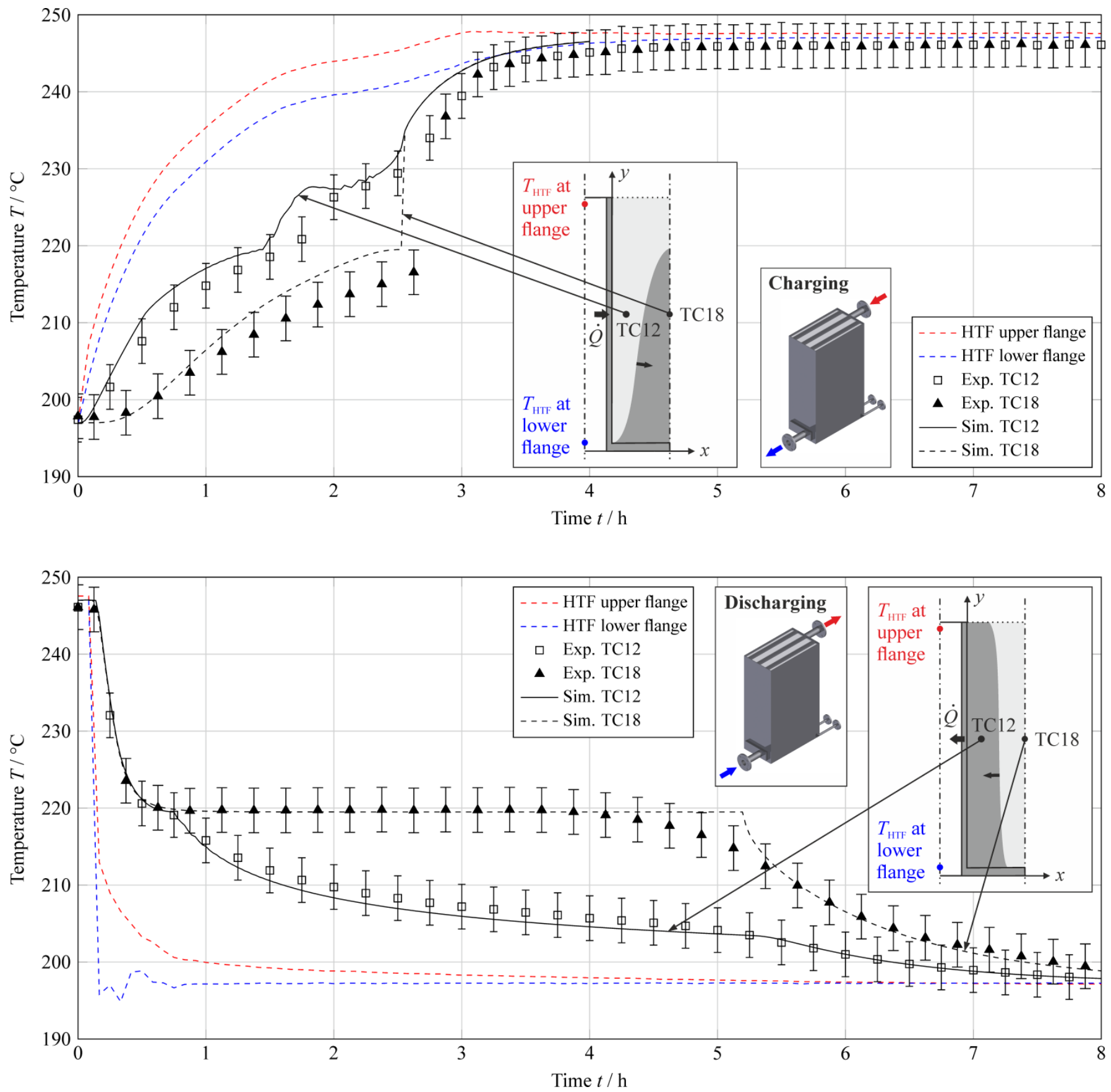

Figure 7: Simulation results compared with experimental data for the charging process (upper graph) and the discharging process (lower graph). Measured temperatures at the upper and lower HTF flanges are shown in red and blue dashed lines, respectively. For the positions TC12 and TC18, respectively, experimental values are shown in symbols and numerical values are shown in lines.

For the discharging case, see the lower graph in Figure 7, most of the simulated temperatures lie within the error uncertainty of the measurements. However, at the end of the phase change process, simulated temperatures for TC18 in the middle of the storage remain at a higher value longer and then drop suddenly. The measured temperatures, on the other hand, decrease slowly over a longer period. This experiment-simulation disparity is a much observed phenomenon for which different explanation attempts are made: 1) Heat losses to the environment neglected in the simulation are more significant than assumed. 2) The thermocouples influence the measured temperatures by interfering with the flow field, affecting the solidification process and contributing to additional heat losses. 3) The technical grade, two-component storage material is not mixed exactly at the eutectic point, but is slightly peritectic and, thus, solidifies in an unstable manner by building dendrites. The dendrites would then grow to the position of the thermocouples gradually, reaching them earlier than a plane phase front, which would lead to an earlier temperature drop. But, compared to the plain phase front, the dendrites would absorb less thermal energy due to their smaller mass, which would lead to a slower decrease in temperature.

For the charging case, see the upper graph in Figure 7, greater deviations are observed. Simulated temperatures remain higher earlier and the phase change jump discontinuities occur earlier. First of all, the charging case is much more prone to errors. The phase change process happens in half the time compared to the discharging case, 
due to the increased heat transfer by natural convection, which leads to a steeper increase in temperature. Additionally, due to the much stronger natural convection, uncertainties in the numerical model lead to larger errors in the simulation results. For the charging case, the following error sources are considered: 1) Heat losses to the environment neglected in the simulation are more significant than assumed. 2) The thermocouples influence the measured temperatures by interfering with the flow field, affecting the melting process and contributing to additional heat losses. 3) Movement of the solid phase with respect to the containment occurs, which is not considered in the simulation.

A quantitative error analysis is done with the mean value $\bar{D}$ of the deviation $D$ between simulation and experiment for all simulation and measurement points $n$ evaluated at the same temperature position:

$D_{i}=\left|T_{\text {sim }}\left(t_{i}\right)-T_{\exp }\left(t_{i}\right)\right|, \quad \bar{D}=\frac{1}{n} \sum_{i=1}^{n} D_{i}$.

To describe the agreement of simulation data to the experiment, accounting for the experimental error tolerance, the mean value $\bar{\xi}$ of the confidence factor $\xi$ is used:

$\xi_{i}=\left\{\begin{array}{ll}1 & D_{i} \leq \theta \\ 0 & D_{i}>\theta\end{array}, \quad \bar{\xi}=\frac{1}{n} \sum_{i=1}^{n} \xi_{i}\right.$.

This factor is already described in [24] and expresses the percentage of simulation points that lie within the error tolerance $\theta$ of temperature measurements. Results of the deviation analysis between simulations and experiments are given in Table 2 .

Table 2: Analysis of deviations of simulations from experiments.

\begin{tabular}{llllll}
\hline & \multicolumn{2}{c}{ Discharge } & & \multicolumn{2}{c}{ Charge } \\
\cline { 2 - 3 } \cline { 5 - 6 } \cline { 5 - 6 } Mean deviation $\bar{D}$ & TC12 & TC18 & & TC12 & TC18 \\
\hline Confidence factor $\bar{\xi}$ & $99 \% \mathrm{~K}$ & $0.7 \mathrm{~K}$ & & $2.3 \mathrm{~K}$ & $3.3 \mathrm{~K}$ \\
& $94 \%$ & & $77 \%$ & $58 \%$ \\
\hline
\end{tabular}

The numbers reveal a small deviation and a high confidence factor for the simulations in the discharging case. In the charging case, the confidence factor is much lower, because the simulation values are just slightly outside of the error tolerance bars for quite a long period. However, the qualitative similarity to the experiments and the low mean deviation attribute the simulation model a high plausibility and sufficient accuracy. This is especially true considering the error sources described earlier in this section. Hence, the deviations are a hint that the simulation model does not fully cover the real physics of the experiment. By improving the simulation model to address these uncertainties or adjusting the experiment to better represent an ideal test case, even higher simulation accuracy is expected.

\section{Numerical parameter study of enclosure dimensions}

With the numerical model, which was described in section 2 and validated in section 4, a parameter study is conducted to find the impact of enclosure dimensions on heat transfer while charging a LHTES system. Discharging is not investigated, because of the minor impact of natural convection in solidification. In the next subsections, the geometry and parameter variation are given and the phase front shapes of different cases are compared. Then a scaling of the melting process is done by dimensional analysis, which, finally, enables an investigation of the impact of natural convection on heat transfer.

\subsection{Geometry and parameter variation}

To investigate the impact of enclosure dimensions on natural convection melting, a parameter study with different widths and heights is conducted. For this purpose, a slightly simplified storage model is dimensioned, as shown in Figure 8.

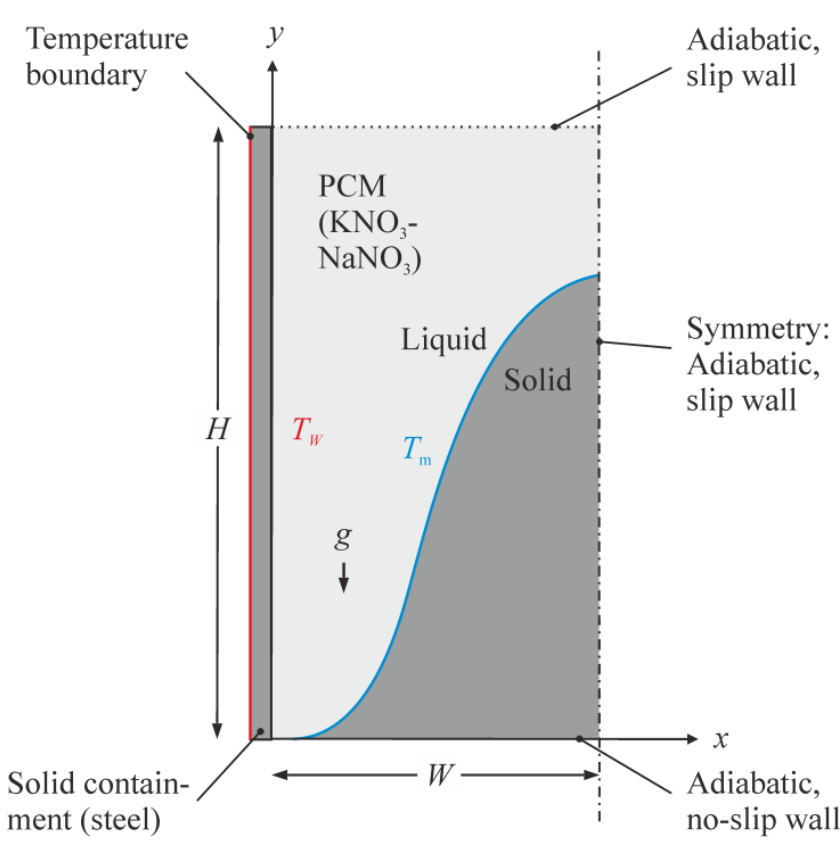

Figure 8: Simulation domain for the parameter study. Compared to the experimental storage system, this simplified domain has a temperature boundary condition at the containment wall and an adiabatic, no slip wall at the PCM bottom. The geometry is defined parametrically in order to vary the height and width of the enclosure.

The domain and boundary conditions are as for the model for the experimental storage unit, described in section 4. However, the influence of a heat conducting bottom plate is neglected and, instead, an adiabatic, no-slip wall boundary condition is set. The boundary condition on the left side is now a temperature boundary condition, neglecting the influence of the heat transfer resistance of the HTF. The material properties are the same as for the experimental storage unit and are found in Table 1 . The boundary temperature is set to a constant value $T_{\mathrm{W}}=$ $232{ }^{\circ} \mathrm{C}$, which is $12.5 \mathrm{~K}$ above the melting temperature of the PCM $\left(219.5^{\circ} \mathrm{C}\right)$. The initial value is $T_{0}=217^{\circ} \mathrm{C}$. The geometry is defined parametrically in order to easily vary the height and width of the enclosure.

A dimensional analysis of this test case reveals the Fourier number $\mathrm{Fo}_{W}$ and the Rayleigh number $\mathrm{Ra}_{W}$, where the width $W$ is used as the characteristic length, the Prandtl number Pr, the Stefan number Ste and the aspect ratio A of height $H$ and width $W$ as non-dimensional groups: 


$$
\begin{aligned}
& \mathrm{Fo}_{W}=\frac{a t}{W^{2}}, \quad \mathrm{Ra}_{W}=\frac{g \beta \Delta T W^{3}}{v a}, \quad \operatorname{Pr}=\frac{v}{a}, \\
& \text { Ste }=\frac{c_{p} \Delta T}{L}, \quad \mathrm{~A}=\frac{H}{W} .
\end{aligned}
$$

These depend on the thermal diffusivity $a$, the time $t$, the kinematic viscosity $v$, the gravity constant $g$, the thermal expansion coefficient $\beta$, the temperature difference between the heated wall and the melting temperature $\Delta T=\left(T_{W}-\right.$ $T_{m}$ ), the specific heat capacity $c_{p}$ and the latent heat of fusion $L$.

The dimensions of rectangular enclosures and the corresponding non-dimensional groups are given in Table 3. The Stefan and Prandtl numbers are constant for all cases with values of Ste $=0.17$ and $\operatorname{Pr}=18.6$.

Table 3: Names, dimensions, aspect ratios and Rayleigh-numbers of all investigated test cases of the parameter study.

\begin{tabular}{llllc}
\hline Case name & $W / \mathrm{mm}$ & $H / \mathrm{mm}$ & $\mathrm{A}=H / W$ & $\mathrm{Ra}_{W}$ \\
\hline W25H12.5 & 25 & 12.5 & 0.5 & $1.5 \cdot 10^{6}$ \\
W25H25 & 25 & 25 & 1 & $1.5 \cdot 10^{6}$ \\
W25H50 & 25 & 50 & 2 & $1.5 \cdot 10^{6}$ \\
W25H100 & 25 & 100 & 4 & $1.5 \cdot 10^{6}$ \\
W25H200 & 25 & 200 & 8 & $1.5 \cdot 10^{6}$ \\
W25H500 & 25 & 500 & 20 & $1.5 \cdot 10^{6}$ \\
W25H1000 & 25 & 1000 & 40 & $1.5 \cdot 10^{6}$ \\
W10H200 & 10 & 200 & 20 & $9.5 \cdot 10^{4}$ \\
W05H200 & 5 & 200 & 40 & $1.2 \cdot 10^{4}$ \\
\hline
\end{tabular}

\subsection{Comparison of the phase front shape}

The phase front is visualized for several different test cases for comparison in Figure 9. For every test case, nine contours show the phase front at a time step that corresponds to a liquid phase fraction $f_{l}$ between 0.1 and 0.9 in steps of 0.1 . The relationship of the liquid phase fraction and instant of time is different for each case, so the figures do not give an impression on the temporal evolution, but rather the different shapes of the phase front at similar liquid phase fractions.

To investigate the influence of the enclosure width, three different widths of 5, 10 and $25 \mathrm{~mm}$ with a fixed height of
$200 \mathrm{~mm}$ are compared to each other in Figure 9 a), b) and c). In the case of W05H200 with a width $W$ of only $5 \mathrm{~mm}$, melting occurs mostly in a horizontal direction; the phase front is nearly vertical for the most part. However, for the test cases with greater widths, W10H200 and W25H200, the phase front is increasingly inclined at higher liquid phase fractions due to natural convection. The heat transfer with natural convection leads to an advective transport of heated fluid to the top, which leads to a temperature gradient from bottom to top. Hence, melting is enhanced at the top and diminished at the bottom.

As expected, natural convection strongly depends on the Rayleigh number $\mathrm{Ra}_{W}$ of the test case and with that also on the width of the enclosure. It is noteworthy that the Rayleigh number is calculated with the enclosure width $W$, but natural convection depends only on the liquid part of the PCM inside the enclosure, which continually increases during melting. Hence, a "transient" Rayleigh number for only the liquid part could be defined that would increase from zero to its maximum value $\mathrm{Ra}_{W}$, given in Table 3 . However, in the opinion of the authors of this article, it is sufficient to use the maximum Rayleigh number, which describes the maximum effect of natural convection.

To assess the influence of the enclosure height, four different selected heights of 200, 100, 50 and $25 \mathrm{~mm}$ with a fixed width of $25 \mathrm{~mm}$ are compared with each other in Figure $9 \mathrm{c}$ ), d), e) and f). A strong influence of natural convection is obvious in all cases, with the phase front becoming strongly inclined with rising liquid phase fractions. It is observed that in the case with a small height W25H25 and an aspect ratio of one, melting occurs at a similar rate in the horizontal as well as the vertical direction. However, for the cases with increasing height, W25H50, $\mathrm{W} 25 \mathrm{H} 100$, and $\mathrm{W} 25 \mathrm{H} 200$, melting increasingly occurs vertically from top to bottom. As soon as the phase front reaches the middle plane, which is the right sides of the figures, melting occurs mostly from top to bottom up to high liquid phase fractions of more than 0.9. As the Rayleigh number $\mathrm{Ra}_{W}$ is fixed for all of these cases, it is seen that the phase front shape also depends on the height or, in nondimensional form, on the aspect ratio A. 


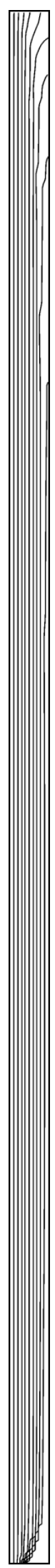

a) $\mathrm{W} 05 \mathrm{H} 200$

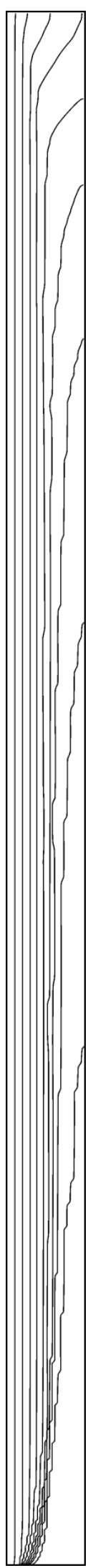

b) $\mathrm{W} 10 \mathrm{H} 200$

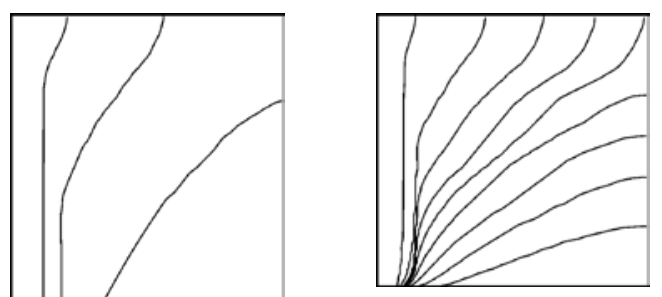

f) $\mathrm{W} 25 \mathrm{H} 25$

$\mathrm{Ra}_{W}=1.5 \cdot 10^{6}, \mathrm{~A}=1$

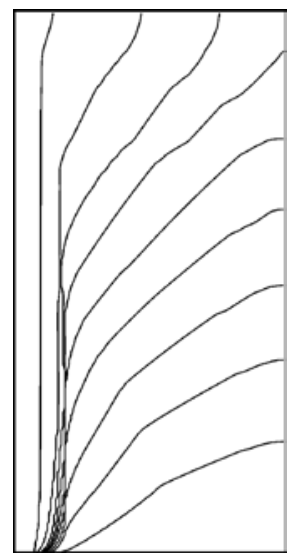

e) $\mathrm{W} 25 \mathrm{H} 50$

$\mathrm{Ra}_{W}=1.5 \cdot 10^{6}, \mathrm{~A}=2$
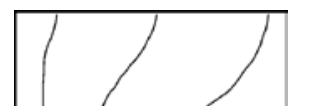

(
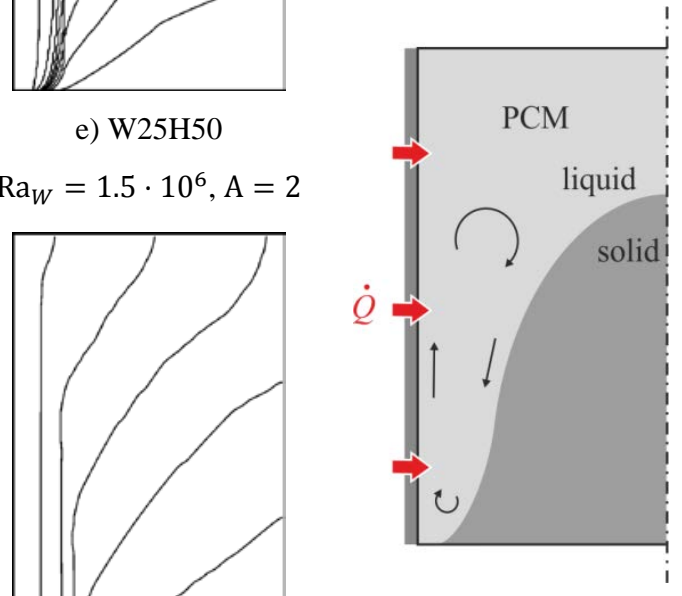

$\mathrm{Ra}_{W}=1.2 \cdot 10^{4}, \mathrm{~A}=40$

$\mathrm{Ra}_{W}=9.5 \cdot 10^{4}, \mathrm{~A}=20$

$\mathrm{Ra}_{W}=1.5 \cdot 10^{6}, \mathrm{~A}=8$

c) $\mathrm{W} 25 \mathrm{H} 200$

Figure 9: Phase front contours during melting for six different test cases. The first three have a common height of $200 \mathrm{~mm}$ and widths of a) $5 \mathrm{~mm}$ b) $10 \mathrm{~mm}$ and c) $25 \mathrm{~mm}$. The last three have a common width of $25 \mathrm{~mm}$ and heights of d) $100 \mathrm{~mm}$, e) $50 \mathrm{~mm}$ and f) $25 \mathrm{~mm}$. For every test case, nine contours are shown at times corresponding to liquid phase fraction values of $f_{l}=0.1,0.2, \ldots 0.9$. 


\subsection{Scaling of the melting process}

The evolution of liquid phase fractions over time for all parameter variations is shown in Figure 10. The melting process is slower with greater widths and heights. Increasing the width increases the resistance to heat transfer by diffusion. However, natural convection becomes relevant after a minimum width and dominant at greater widths. But the heat transfer enhancement by natural convection does not compensate the higher diffusive heat resistance, which leads to slower melting with greater widths. Varying the height leads to similar findings. While flow velocities due to natural convection increase with the height, the heat transfer decreases due to longer heat transfer paths from the heat source (heated wall) to the heat sink (phase front).

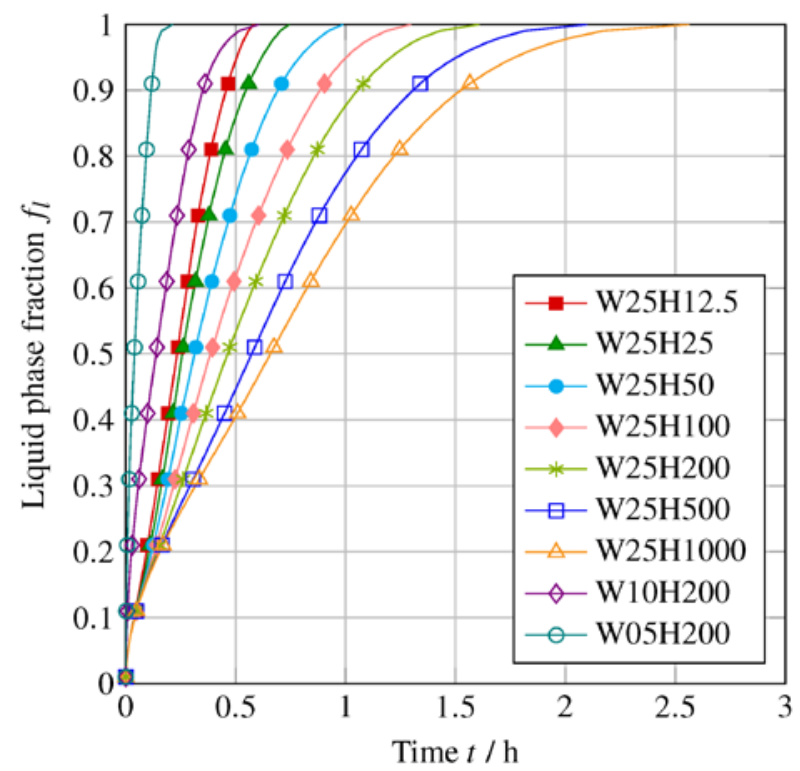

Figure 10: Liquid phase fractions of all test cases during melting plotted over time.

The liquid phase fraction over time is now scaled with the relevant non-dimensional groups $\mathrm{Fo}, \mathrm{Ra}_{W}$, and $\mathrm{A}$ in a similar approach as by Shatikian, Ziskind and Lethan $[19,20]$. However, the Stefan number Ste is disregarded, because it is constant in this investigation. Instead, the aspect ratio $\mathrm{A}$ is included. A good scaling is obtained by trial and error with exponents of 1 for Fo, 1/6 for $\mathrm{Ra}_{W}$ and $-1 / 4$ for $\mathrm{A}$. The result is shown in Figure 11.

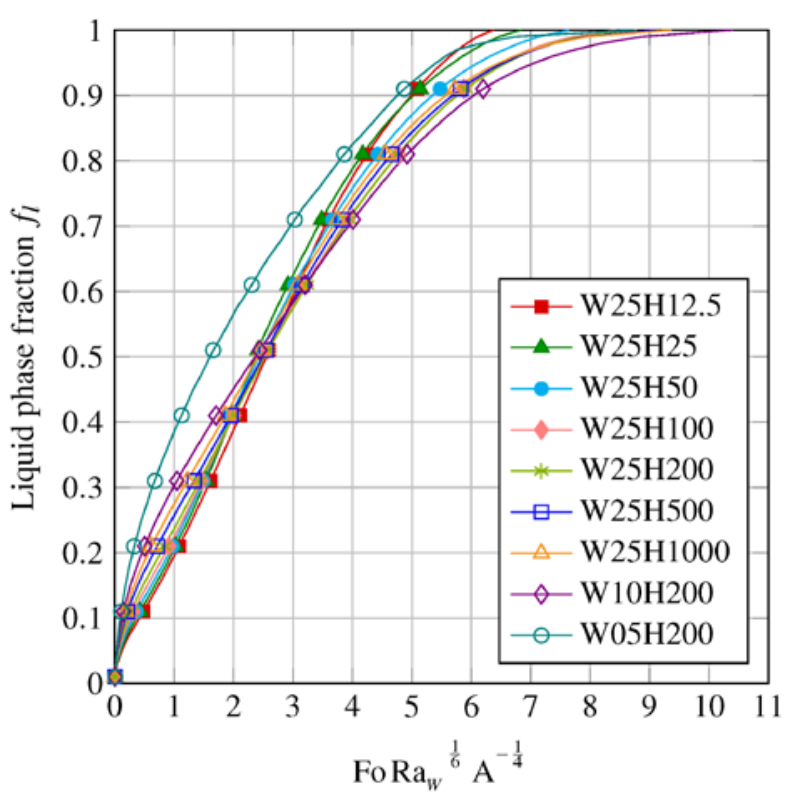

Figure 11: Scaled liquid phase fractions of all test cases during melting, plotted over the relevant non-dimensional groups.

In literature, the exponent of the Rayleigh number $\mathrm{Ra}_{W}$ in Nusselt correlations for single phase natural convection is usually found as 1/4, e.g. by Kutateladze [32]. Exactly this value is also used here for different widths at constant height, when the width $W$ in the aspect ratio $\mathrm{A}=H / W$ is included in the Rayleigh number $\mathrm{Ra}_{W}$. However, the inclusion of the aspect ratio $\mathrm{A}$ in the investigation leads to an exponent of $1 / 6$ for $\mathrm{Ra}_{W}$.

After scaling, the curves mostly coincide, excepting the case with the smallest width. Its greater deviations are suspected to be due to heat conduction being dominant and therefore scaling with the Rayleigh number overestimates the impact of natural convection.

\subsection{The impact of natural convection on heat transfer}

To analyze the impact of natural convection, a convective enhancement factor is defined as the ratio of the actual heat flux with natural convection to a hypothetical heat flux by heat conduction only:

$\epsilon\left(f_{l}\right)=\frac{\dot{Q}\left(f_{l}\right)}{\dot{Q}_{\text {cond }}\left(f_{l}\right)}$.

To calculate this parameter, the heat transfer rates of two different simulations - one with natural convection $(\dot{Q})$ and one with only heat conduction $\left(\dot{Q}_{\text {cond }}\right)$ - are evaluated. In the simulation of heat conduction, only the energy equation (4) is solved instead of the whole system of equations (1), (2) and (4). Since the time scale and the phase front shapes are different in each simulation, they are both evaluated at times with equal liquid phase fractions $f_{l}$. The resulting convective enhancement factors are shown in Figure 12 for all parameter variations. 


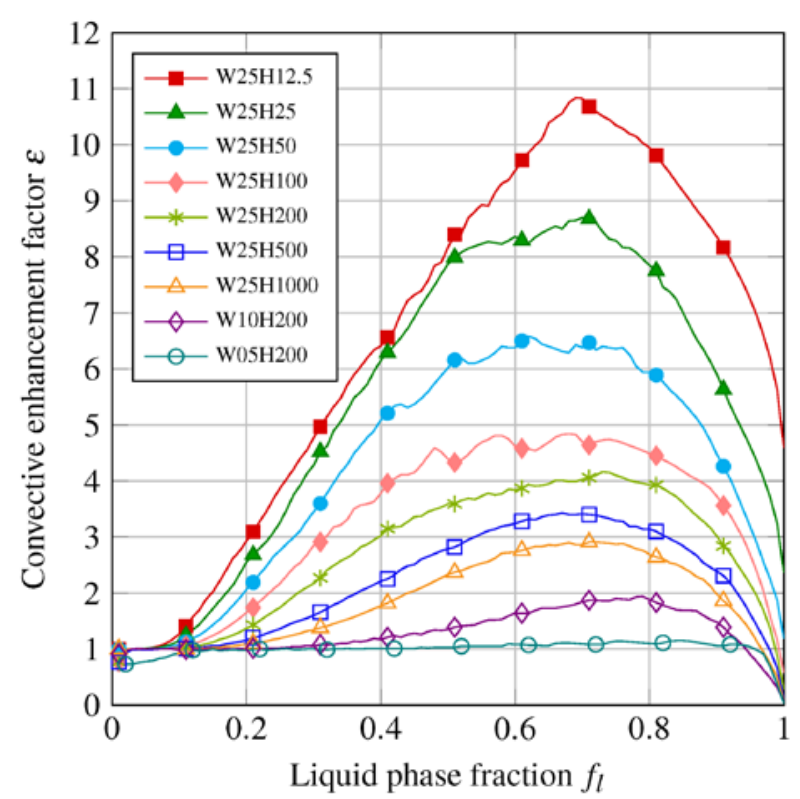

Figure 12: Convective enhancement factor of all test cases during melting plotted over the liquid phase fraction.

For the case with the smallest width of $5 \mathrm{~mm}$ and height of $200 \mathrm{~mm}$, a small value of $\epsilon$ near unity is found, which means that heat transfer occurs mostly by conduction. With increasing width, but constant height, the heat transfer enhancement by convection increases significantly up to a maximum value of four for a width of $25 \mathrm{~mm}$. With increasing height at constant width, heat transfer enhancement decreases slightly until a factor of three for a height of $1000 \mathrm{~mm}$. With decreasing height, it increases up to a maximum value of 11 for the smallest height of $12.5 \mathrm{~mm}$. However, this trend is expected to reverse at even smaller heights. When the height is decreased to a size of the order of the boundary layer thickness at the wall, fluid flow will stagnate and the convective enhancement factor will eventually decrease back to unity.

To quantify the convective enhancement factor, its mean value $\bar{\epsilon}$ is calculated for each case and plotted over the relevant non-dimensional groups $\mathrm{Ra}_{W}$ and $\mathrm{A}$ in Figure 13.

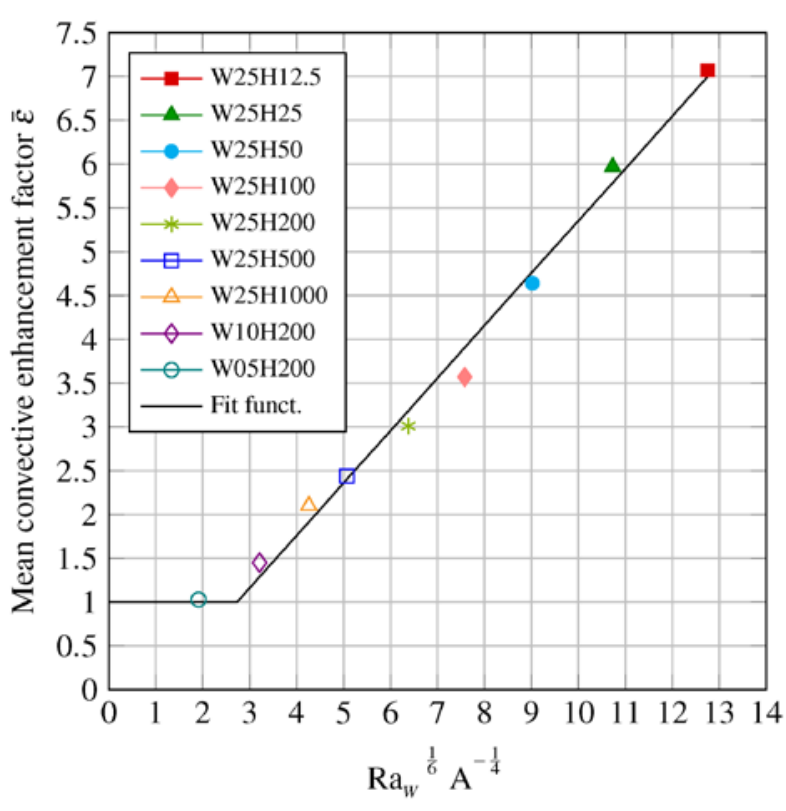

Figure 13: Mean convective enhancement factors of all test cases during melting, plotted over the relevant non-dimensional groups.

The mean convective enhancement factor $\bar{\epsilon}$ is an estimation of the impact of natural convection on the whole charging process. For example, in the case W25H200, heat transfer by natural convection is about three times as much as it would be by only heat conduction. Since the data points suggest a linear relationship, a linear fit function is computed. It is bounded by the minimum value of the convective enhancement factor, $\bar{\epsilon}=1$, where the heat flow rate by natural convection equals that of hypothetical pure heat conduction. Hence, the influence of natural convection vanishes at this point. The value $\bar{\epsilon}=1$ is reached by the linear fit at a value of 2.73 , which leads to the following criterion for the occurrence of natural convection:

$\operatorname{Ra}_{W}{ }^{\frac{1}{6}} \mathrm{~A}^{-\frac{1}{4}} \geq 2.73$.

With this, the linear fit is completely described by the function

$\bar{\epsilon}=\left\{\begin{array}{cl}1 & \mathrm{Ra}_{W}{ }^{\frac{1}{6}} \mathrm{~A}^{-\frac{1}{4}}<2.73 \\ 0.57\left(\mathrm{Ra}_{W}{ }^{\frac{1}{6}} \mathrm{~A}^{-\frac{1}{4}}\right)-0.38 & \mathrm{Ra}_{W}{ }^{\frac{1}{6}} \mathrm{~A}^{-\frac{1}{4}} \geq 2.73\end{array}\right.$,

which predicts both the occurrence and strength of natural convection during the melting process while charging a flat plate LHTES.

However, natural convection will not affect the melting process from the beginning, but rather start at a distinct point. This is defined as the critical liquid phase fraction $f_{\text {crit }}$. An expression for the onset of natural convection in a vertical air cavity, which is heated from one side and cooled from the other side, is given by Batchelor [33],

$\mathrm{Ra}_{W_{l}} \geq 500 \mathrm{~A}_{l}$

where the index $l$ is introduced to indicate that this equation can only be applied to a liquid region that gradually changes during the melting process. From this equation, a critical liquid phase fraction for the onset of natural convection while melting may be approximately derived: A rectangular region with the full height of the enclosure is assumed for 
the liquid region, $H_{l}=H$, as it would be the case in the melting process with only heat conduction. The width of the liquid is then the product of the enclosure width and the liquid phase fraction $W_{l}=f_{l} W$. With this assumption, the relation (18) is expressed in terms of the enclosure dimensions and rearranged to obtain the critical liquid phase fraction:

$f_{l, \text { crit }}=\sqrt[4]{\frac{500 \mathrm{~A}}{\mathrm{Ra}_{W}}}$.

Because of the assumption on the shape of the liquid region and the fact that equation (18) is actually derived from an experiment of an air cavity between a heated and a cooled plate, the validity of equation (19) for the present case is limited. However, we keep equation (19) in mind and derive a similar equation from the simulation data obtained in this study.

The critical liquid phase fraction can be obtained from the convective enhancement factor $\epsilon$, see Figure 12: The critical value is defined at that liquid phase fraction, where the convective enhancement factor $\epsilon$ first exceeds an arbitrarily defined value of 1.15 . The resulting critical liquid phase fraction for all test cases is plotted in Figure 14 with logarithmic axes.

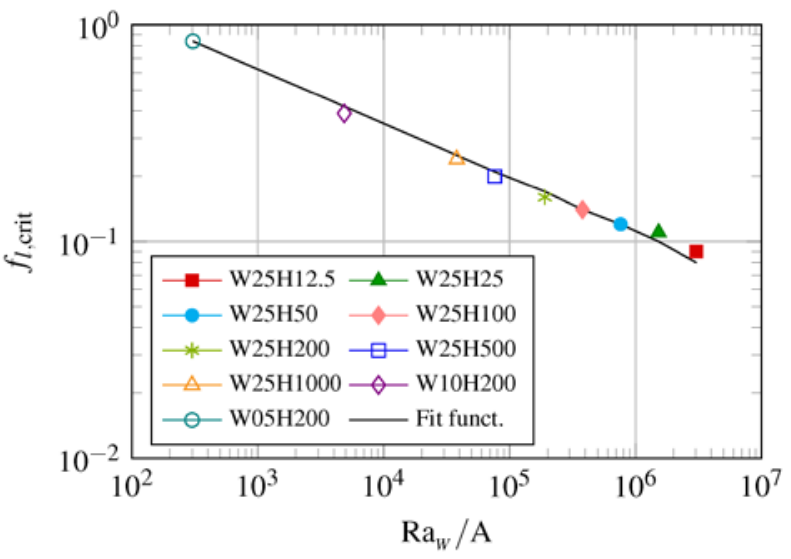

Figure 14: Critical liquid phase fraction for the onset of natural convection of all test cases during melting plotted over the fraction of $\mathrm{Ra}_{W}$ and $\mathrm{A}$.

By adjusting the constant in equation (19), a linear fit function,

$f_{l, \text { crit }}=\sqrt[4]{\frac{150 \mathrm{~A}}{\mathrm{Ra}_{W}}}$,

is found to fit the data well. This function for the critical liquid phase fraction is also plotted in Figure 14.

With the presented analysis, the influence of natural convection during charging can be predicted and included in the design process of a flat plate LHTES: The occurrence and heat transfer enhancement of natural convection is characterized by the mean convective enhancement factor in equation (17). For those cases, where natural convection occurs, the critical liquid phase fraction for the onset of natural convection during the melting process is given by equation (20).

\section{Conclusions}

A numerical fluid flow and heat transfer model for natural convection with melting and solidification was applied to simulate an experimental flat plate latent heat thermal energy storage system. A comparison of the numerical model with experimental measurements for the melting process (while charging) and the solidification process (while discharging) demonstrate the plausibility of the model and yield reasonable accuracy. However, certain deviations were observed that should be investigated further with specific validation experiments that allow insight into the underlying flow and heat transfer mechanisms.

A numerical parameter study was performed to determine the influence of enclosure dimensions on melting with natural convection. Nine different test cases with various widths and heights simulate a test melting problem. This study includes a large range of aspect ratios and Rayleigh numbers. With dimensional analysis, the results were scaled by the relevant non-dimensional groups.

The influence of natural convection on the heat transfer rate was assessed with the newly introduced convective enhancement factor, which is defined as the ratio of actual heat flux by natural convection to a hypothetical heat flux by conduction only. Evaluated for the parameter study, it clearly indicates the impact of enclosure dimensions on melting with natural convection. By curve-fitting, a correlation function for the mean convective enhancement factor and the critical liquid phase fraction for natural convection onset were found.

The presented results enable the design of a flat plate LHTES considering the effect of natural convection. The onset of natural convection and the enhancement of charging power can be estimated directly from simple analytical correlation functions including the Rayleigh number and the aspect ratio of the enclosure height and width. The results indicate that heat transfer enhancement due to natural convection increases with greater widths and smaller heights of storage material enclosures. Hence, the vertical segmentation of high enclosures into smaller ones should be considered to enhance heat transfer during charging.

\section{References}

[1] International Energy Agency (IEA). Technology Roadmap: Energy storage. 2014.

[2] Jegadheeswaran S, Pohekar SD, Kousksou T. Exergy based performance evaluation of latent heat thermal storage system: A review. Renew Sustain Energy Rev 2010;14:2580-95. doi:10.1016/j.rser.2010.07.051.

[3] Agyenim F, Hewitt N, Eames P, Smyth M. A review of materials, heat transfer and phase change problem formulation for latent heat thermal energy storage systems (LHTESS). Renew Sustain Energy Rev 2010;14:615-28. doi:10.1016/j.rser.2009.10.015.

[4] Kenisarin MM. High-temperature phase change materials for thermal energy storage. Renew Sustain Energy Rev 2010;14:955-70. doi:10.1016/j.rser.2009.11.011.

[5] Sharma A, Tyagi VV, Chen CR, Buddhi D. Review on thermal energy storage with phase change materials and applications. Renew Sustain Energy Rev 2009;13:318-45. doi:10.1016/j.rser.2007.10.005.

[6] Mehling H, Cabeza LF. Heat and cold storage with PCM. 
Berlin Heidelberg: Springer; 2008. doi:10.1007/978-3540-68557-9.

[7] Zalba B, Marín JM, Cabeza LF, Mehling H. Review on thermal energy storage with phase change: materials, heat transfer analysis and applications. Appl Therm Eng 2003;23:251-83. doi:10.1016/S1359-4311(02)00192-8.

[8] Pereira da Cunha J, Eames P. Thermal energy storage for low and medium temperature applications using phase change materials - A review. Appl Energy 2016;177:227_ 38. doi:10.1016/j.apenergy.2016.05.097.

[9] Xu B, Li P, Chan C. Application of phase change materials for thermal energy storage in concentrated solar thermal power plants: A review to recent developments. Appl Energy 2015;160:286-307. doi:10.1016/j.apenergy.2015.09.016.

[10] Laing D, Bahl C, Bauer T, Lehmann D, Steinmann WD. Thermal energy storage for direct steam generation. Sol Energy 2011;85:627-33.

doi:10.1016/j.solener.2010.08.015.

[11] Johnson M, Vogel J, Hempel M, Dengel A, Seitz M, Hachmann B. High temperature latent heat thermal energy storage integration in a co-gen plant. Energy Procedia 2015;73:281-8.

[12] Szekely J, Chhabra PS. The effect of natural convection on the shape and movement of the melt-solid interface in the controlled solidification of lead. Metall Mater Trans 1970;1:1195-203. doi:10.1007/BF02900231.

[13] Hale N, Viskanta R. Photographic observation of the solid-liquid interface motion during melting of a solid heated from an isothermal vertical wall. Lett Heat Mass Transf 1978;5:329-37.

[14] Dhaidan NS, Khodadadi JM. Melting and convection of phase change materials in different shape containers: A review. Renew Sustain Energy Rev 2015;43:449-77. doi:10.1016/j.rser.2014.11.017.

[15] Bareiss M, Beer H. Experimental investigation of melting heat transfer with regard to different geometric arrangements. Int Commun Heat Mass Transf 1984;11:323-33. doi:10.1016/0735-1933(84)90060-5.

[16] Benard C, Gobin D, Martinez F. Melting in rectangular enclosures: experiments and numerical simulations. J Heat Transfer 1985;107. doi:10.1115/1.3247506.

[17] Jany P, Bejan A. Scaling theory of melting with natural convection in an enclosure. Int J Heat Mass Transf 1988;31:1221-35. doi:10.1016/0017-9310(88)90065-8.

[18] Farid MM, Husian RM. An electrical storage heater using the phase-change method of heat storage. Energy Convers Manag 1990;30:219-30. doi:10.1016/01968904(90)90003-H.

[19] Shatikian V, Ziskind G, Letan R. Numerical investigation of a PCM-based heat sink with internal fins. Int J Heat Mass Transf 2005;48:3689-706. doi:10.1016/j.ijheatmasstransfer.2004.10.042.

[20] Shatikian V, Ziskind G, Letan R. Numerical investigation of a PCM-based heat sink with internal fins: Constant heat flux. Int J Heat Mass Transf 2008;51:1488-93. doi:10.1016/j.ijheatmasstransfer.2007.11.036.

[21] Dutil Y, Rousse DR, Salah N Ben, Lassue S, Zalewski L. A review on phase-change materials: Mathematical modeling and simulations. Renew Sustain Energy Rev 2011;15:112-30. doi:10.1016/j.rser.2010.06.011.

[22] Voller VR. An Overview of Numerical Methods for Solving Phase Change Problems. In: Minkowycz WJ, Sparrow EM, editors. Adv. Numer. HEAT Transf. Vol. 1, Taylor \& Francis; 1997, p. 341-80.

[23] Voller VR, Swaminathan CR, Thomas BG. Fixed grid techniques for phase change problems: A review. Int J Numer Methods Eng 1990;30:875-98. doi:10.1002/nme.1620300419.

[24] Pointner H, de Gracia A, Vogel J, Tay NHS, Liu M, Johnson $\mathrm{M}$, et al. Computational efficiency in numerical modeling of high temperature latent heat storage : Comparison of selected software tools based on experimental data. Appl Energy 2016;161:337-48. doi:10.1016/j.apenergy.2015.10.020.

[25] Voller V, Prakash C. A fixed grid numerical modelling methodology for convection-diffusion mushy region phase-change problems. Int J Heat Mass Transf 1987;30:1709-19. doi:10.1016/0017-9310(87)90317-6.

[26] Brent AD, Voller VR, Reid KJ. ENTHALPY-POROSITY TECHNIQUE FOR MODELING CONVECTIONDIFFUSION PHASE CHANGE : APPLICATION TO THE MELTING OF A PURE METAL. Numer Heat Transf An Int J Comput Methodol 1988;13:297-318. doi:10.1080/10407788808913615.

[27] Shmueli H, Ziskind G, Letan R. Melting in a vertical cylindrical tube: Numerical investigation and comparison with experiments. Int J Heat Mass Transf 2010;53:4082_ 91. doi:10.1016/j.ijheatmasstransfer.2010.05.028.

[28] ANSYS Inc. ANSYS Fluent User’s Guide 2015.

[29] Patankar S. NUMERICAL HEAT TRANSFER AND FLUID FLOW. Hemisphere Publishing; 1980.

[30] Johnson M, Fiss M, Klemm T, Eck M. Test and analysis of a flat plate latent heat storage design. Energy Procedia, vol. 57, 2013, p. 662-71. doi:10.1016/j.egypro.2014.10.221.

[31] Johnson M, Fiß M, Klemm T. Experimental Testing of Various Heat Transfer Structures in a Flat Plate Thermal Energy Storage Unit. SolarPACES, 2015.

[32] Kutateladze SS. Natural convection. A Concise Encycl. Heat Transf., 1966, p. 166-75.

[33] Batchelor GK. Heat transfer by free convection across a closed cavity between vertical boundaries at different temperatures. Q Appl Math 1954;12:209-33. 